\title{
Determinação do ponto de colheita na produção de sementes de pimenta malagueta e alterações bioquímicas durante 0 armazenamento e a germinação
}

\section{Determination of harvest for seed production of chilli and biochemical changes during storage and germination}

\section{Franciele CAIXETA ${ }^{1}$; Édila Vilela de Resende VON PINHO $^{2}$; Renato Mendes GUIMARÃES ${ }^{3}$; Pedro Henrique Andrade Rezende PEREIRA ${ }^{4}$; Hugo Cesar Rodrigues Moreira CATÃO ${ }^{5}$; Aline da Consolação Sampaio CLEMENTE ${ }^{6}$}

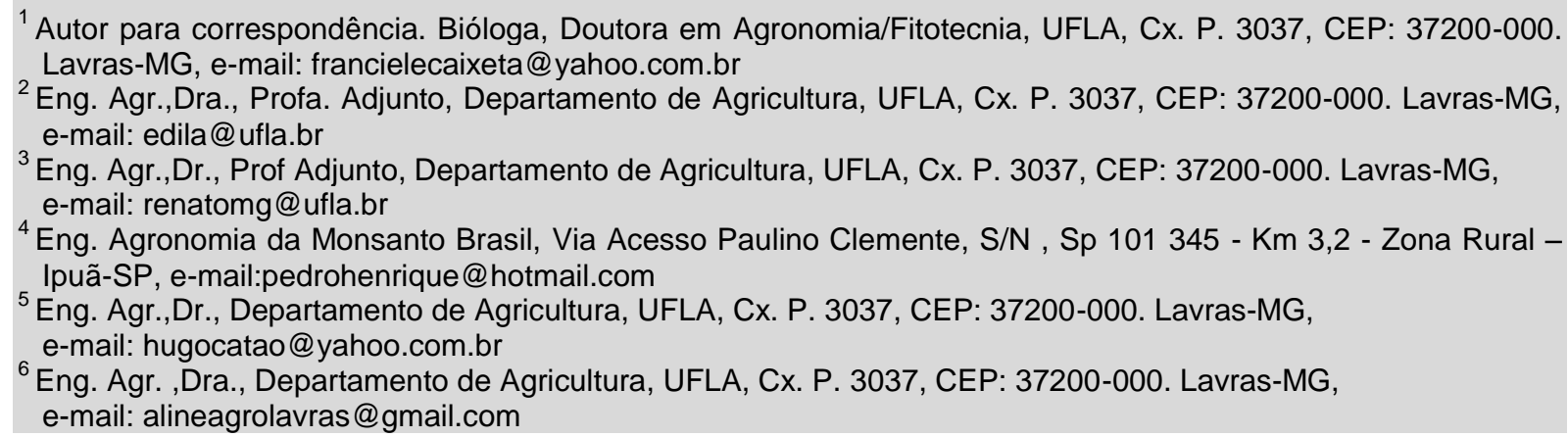

\section{Recebido em: 25-11-2013; Aceito em: 27-03-2014}

\section{Resumo}

O ponto de colheita interfere na qualidade das sementes, sendo que em espécies com frutos carnosos e maturação desuniforme, existe dificuldade na definição do mesmo. Objetivou-se avaliar a dormência em sementes de pimenta malagueta em três estádios de maturação durante o armazenamento, visando à determinação do melhor ponto de colheita e semeadura, e também avaliar alterações enzimáticas durante o processo de germinação das sementes processadas em diferentes estádios de maturação, durante 0 armazenamento. As sementes foram extraídas manualmente de frutos em três estádios de desenvolvimento: E1 (frutos com primeiros sinais de amarelecimento), E2 (frutos maduros) e E3 (Frutos maduros e submetidos a sete dias de repouso). Após a secagem as sementes com $8 \%$ de teor de água foram armazenadas em câmara fria por períodos de 0,4 e 8 meses. Após estes períodos a qualidade das sementes foi avaliada por meio dos testes de germinação, vigor e atividades enzimáticas. Para a avaliação da atividade das enzimas, durante a germinação das sementes, de cada tratamento, as sementes de cada tratamento foram amostradas, por períodos de 0,48 , 96 e 144 horas após a semeadura. Empregou-se delineamento de blocos casualizados, em ensaio fatorial 3 épocas de colheita $\times 3$ períodos de armazenamento com quatro repetições. Existe dormência em sementes de pimenta malagueta principalmente quando recém-armazenadas e é superada aos quatro meses de armazenamento. Sementes de pimenta malagueta devem ser colhidas no estádio E3 quando forem comercializadas logo após o processamento e nos estádios E2 ou E3 quando armazenadas por períodos acima de quatro meses. As alterações enzimáticas são evidentes no processo de germinação e nos diferentes estádios de maturação durante o armazenamento.

Palavras-chave adicionais: Capsicum frutescens; maturação de sementes; qualidade de sementes.

\begin{abstract}
The harvest point interferes with the quality of the seeds, and in species with fleshy fruits and irregular maturation, there is difficulty in defining it. This study aimed to assess the dormancy of chili in three maturity stages during storage, in order to determine the best point of reaping and sowing and also enzymatic changes during the process of seed germination processed in different stages of maturation during storage. The seeds were manually extracted from fruits at three developmental stages: E1 (fruits with first signs of yellowing), E2 (ripe fruit) and E3 (mature and subjected to seven days of rest Fruits). After drying the seeds with $8 \%$ water content were stored in cold storage for 0,4 and 8 months. After these periods seed quality was evaluated by means of the germination, vigor and enzyme activity tests. For the evaluation of the enzymes during the germination of seeds from each treatment, the seeds of each treatment were sampled for periods of $0,48,96$ and 144 hours after sowing. We used a randomized block design, factorial trial 3 harvest times $\times 3$ storage periods with
\end{abstract}


four replications. There dormancy in seeds of chillies especially when newly stored and is surmounted by four months of storage. Chili seeds should be harvested when the E3 stage are sold after processing and at E2 or E3 when stored for periods up to four months. Enzyme changes are evident in the germination process and the different stages of maturation during storage.

Additional keywords: Capsicum frutescens; seed maturation; seed quality.

\section{Introdução}

O cultivo de pimentas, considerado até pouco tempo como atividade secundária, tem passado por grandes transformações e assumido grande importância no país. Essas transformações visam atender às demandas internas $e$ externas do mercado consumidor. A agregação de valor ao produto seja na forma de molhos, conservas, geléias, pimenta desidratada em pó para fabricação de corantes e temperos, dentre outras tem contribuído para a ampliação do setor (CAIXETA et al., 2014).

O aumento no consumo de pimentas deve-se a estudos que comprovaram que pimentas apresentam teores de vitamina $\mathrm{A}$ e C superiores aos encontrados no pimentão e demais olerícolas produzidas no Brasil (FILGUEIRA, 2000; FILGUEIRA, 2003). Em consequência do aumento no mercado de pimentas tem sido observado aumento na área plantada, o que consequentemente exige maior demanda por sementes de qualidade.

Por ser um mercado recente e emergente existe grande necessidade de pesquisa em tecnologia de produção de sementes para a obtenção de sementes com alta qualidade genética, física, fisiológica e sanitária, gerando maior uniformidade e vigor das plântulas e, consequentemente maior produtividade final. Essa adoção de novas tecnologias requer o conhecimento dos fatores que interferem na obtenção de sementes de pimenta com elevada qualidade fisiológica, havendo a necessidade de estudar as alterações fisiológicas e bioquímicas que ocorrem durante o processo de germinação.

A produção de sementes é uma atividade especializada e cuidados devem ser tomados em todas as fases de produção para assegurar a obtenção de lotes de sementes com alta qualidade. Um dos fatores que interfere na qualidade de sementes é o ponto de colheita, sendo que em espécies com frutos carnosos e com maturação desuniforme dos frutos, a exemplo de pimenta, existe dificuldade na definição do mesmo (VIDIGAL et al., 2006 e DIAS et al. 2006a). Nessas espécies há a necessidade de avaliar a alteração fisiológica das sementes durante o desenvolvimento fornecendo subsídios para a determinação do momento de colheita das sementes.

Um aspecto importante da produção de sementes é a determinação da maturidade fisiológica e do momento ideal de colheita, visando obter sementes de alta qualidade (NASCIMENTO et al.,2006). Como as espécies de pimenta apresentam florescimento contínuo, na mesma planta existem frutos em diferentes estádios de maturação, o que dificulta a determinação da época de colheita, visando à obtenção de sementes de alta qualidade. A idade e a coloração dos frutos têm sido os principais parâmetros empregados para identificar em campo não só a ocorrência da maturidade fisiológica das sementes, mas também o ponto ideal para colheita (ALBUQUERQUE et al., 2009).

Assim, nessa pesquisa objetivou-se avaliar a dormência em sementes de pimenta malagueta em três estádios de maturação durante o armazenamento, visando à determinação do meIhor ponto de colheita e semeadura, e também avaliar alterações enzimáticas durante o processo de germinação das sementes processadas em diferentes estádios de maturação, durante 0 armazenamento.

\section{Material e métodos}

A pesquisa foi conduzida em área experimental, Latitude $21^{\circ} 14^{\prime} \mathrm{S}$ e Longitude $40^{\circ} 17^{\prime} \mathrm{W}$ e a $918,8 \mathrm{~m}$ de altitude e no Laboratório Central de Sementes do Departamento de Agricultura da Universidade Federal de Lavras. A temperatura média anual do ar é de 19,4 ํㅡ e a pluviosidade se distribuem principalmente de outubro a abril, com valores anuais médios de 1529,7 mm.

Em uma primeira etapa da pesquisa foram formadas mudas de pimenta para a instalação do experimento no campo. Para isso as sementes de pimenta malagueta (Capsicum frutescens), foram semeadas em bandejas de "isopor" com 72 células, contendo substrato comercial Plantimax® - hortaliças e $5 \mathrm{~mL}$ de solução de 2000 ppm de sulfato de amônio por célula. Após 45 dias da semeadura, foi realizado o transplantio das mudas para área experimental com Latossolo vermelho-escuro (LE), textura argilosa.

O solo foi preparado convencionalmente e as correções foram feitas de acordo com a análise química do mesmo. Os ensaios foram instalados em delineamento de blocos casualizados (DBC) com quatro repetições. Cada parcela constou de duas linhas de $5 \mathrm{~m}$ de comprimento com 5 plantas 
por metro, espaçadas de 1,5 m entre linhas.

O cultivo das plantas foi realizado conforme FILGUEIRA (2005). As sementes foram extraídas manualmente de frutos em três estádios de desenvolvimento: E1 (frutos com os primeiros sinais de amarelecimento), E2 (frutos maduros) e E3 (frutos maduros e submetidos a sete dias de repouso). Em seguida as sementes foram secadas em estufa com circulação de ar a $35 \stackrel{\circ}{\circ}$ até atingirem $8 \%$ de teor de água.

As sementes correspondentes a cada estádio de desenvolvimento foram acondicionadas em embalagens semi - impermeáveis (sacos de plástico) e armazenadas em câmara fria a $10 \stackrel{\circ}{\mathrm{C}} \mathrm{e}$ $50 \%$ de umidade relativa por períodos de zero, quatro e oito meses após a secagem. Ao fim de cada época de armazenamento foi avaliada a qualidade das sementes de pimenta por meio dos testes de germinação (BRASIL, 2009); emergência de plântulas (MAGUIRE, 1962); condutividade elétrica (VIDIGAL et al., 2008) e envelhecimento acelerado (TORRES, 2005). As sementes remanescentes do teste de germinação (sementes que não germinaram) foram submetidas ao teste de tetrazólio (BRASIL, 2009).

Foi avaliada ainda a atividade das enzimas esterase, superóxido desmutase (SOD), peroxidase, malato desidrogenase (MDH), álcool desidrogenase (ADH), a-amilase (ALFENAS, 2006) e endo- $\beta$-mananase (DOWNIE et al., 1994). A qualidade também foi avaliada em sementes recémarmazenadas (período zero de armazenamento). Para as análises eletroforéticas das enzimas durante a germinação, as sementes foram germinadas de acordo com o teste de germinação e nos períodos de 0, 48, 96 e 144 horas após a semeadura as sementes e foram trituradas na presença de polivinilpirrolidona (PVP) e nitrogênio líquido em mortar sobre gelo e posteriormente armazenadas à temperatura de $86 \stackrel{\circ}{\circ}$.

$\mathrm{O}$ delineamento experimental utilizado foi 0 de blocos casualizados, em esquema fatorial $3 \times 3$, sendo os fatores: estádio de desenvolvimento do fruto (E1, E2 e E3) e períodos de armazenamento (0, 4 e 8 meses). Foi realizada a análise de variância para todos os testes, utilizando o programa estatístico Sisvar (FERREIRA, 2000). Para a comparação entre as médias, foi utilizado o Teste de Scott-Knott a 5\% de probabilidade.

\section{Resultados e discussão}

O teor de água das sementes acondicionadas em embalagens impermeáveis de plástico foi monitorado durante o armazenamento e, independentemente do estádio de desenvolvimento verificou-se manutenção do mesmo em $8 \%$.

Menores valores de germinação foram observados nas sementes processadas no primeiro estádio de desenvolvimento (E1), em todos os períodos de armazenamento (Tabela 1). Nos períodos de 0 e 8 meses de armazenamento não houve diferença entre os valores de germinação observados nas sementes processadas nos estádios E2 e E3 de desenvolvimento. Já aos quatro meses de armazenamento maiores valores de germinação foram observados em sementes processadas no estádio de desenvolvimento E3 (Tabela 1).

Tabela 1 - Valores médios de germinação; emergência de plântulas; índice de velocidade de emergência (IVE) e de vigor, obtido pelo teste de envelhecimento acelerado, de sementes de pimenta malagueta colhidas nos estádios de frutos amarelados (E1), de frutos maduros (E2) e de frutos maduros com 7 dias de repouso (E3), ao longo do armazenamento. Mean values of germination, emergence, speed of emergence index and force obtained by accelerated aging of seeds of chillies harvested at different stages of development, during storage.

\begin{tabular}{|c|c|c|c|}
\hline \multirow{3}{*}{ Estádios } & \multicolumn{3}{|c|}{ Períodos de armazenamento (meses) } \\
\hline & 0 & 4 & 8 \\
\hline & \multicolumn{3}{|c|}{ Germinação (\%) } \\
\hline $\mathrm{E} 1$ & $3 \mathrm{~B} \mathrm{~b}$ & $40 \mathrm{C} \mathrm{a}$ & $11 \mathrm{~B} \mathrm{~b}$ \\
\hline E2 & $13 \mathrm{AC}$ & $55 \mathrm{~B} \mathrm{a}$ & $42 \mathrm{~A} \mathrm{~b}$ \\
\hline E3 & $22 \mathrm{AC}$ & $67 \mathrm{~A} \mathrm{a}$ & $50 \mathrm{Ab}$ \\
\hline \multicolumn{4}{|c|}{ Emergência (\%) } \\
\hline E1 & $52 \mathrm{C} \mathrm{b}$ & $69 \mathrm{~A} \mathrm{a}$ & $54 \mathrm{~B} \mathrm{~b}$ \\
\hline E2 & $68 \mathrm{~A} a$ & $76 \mathrm{~A} \mathrm{a}$ & $71 \mathrm{~A} \mathrm{a}$ \\
\hline E3 & $60 \mathrm{~B} \mathrm{~b}$ & $71 \mathrm{~A} \mathrm{a}$ & $75 \mathrm{~A} \mathrm{a}$ \\
\hline \multicolumn{4}{|c|}{ IVE } \\
\hline E1 & $9 \mathrm{~B} \mathrm{C}$ & $19 \mathrm{~B} \mathrm{a}$ & $16 \mathrm{~B} \mathrm{~b}$ \\
\hline E2 & $20 \mathrm{~A} \mathrm{~b}$ & $27 \mathrm{~A} \mathrm{a}$ & $26 \mathrm{~A} \mathrm{a}$ \\
\hline E3 & $18 \mathrm{Ac}$ & $24 \mathrm{Ab}$ & $28 \mathrm{~A} \mathrm{a}$ \\
\hline \multicolumn{4}{|c|}{ Envelhecimento acelerado (\%) } \\
\hline E1 & $5 \mathrm{~B} \mathrm{~b}$ & $49 \mathrm{~B} \mathrm{a}$ & $40 \mathrm{~B} \mathrm{a}$ \\
\hline E2 & $9 \mathrm{~B} \mathrm{~b}$ & $63 \mathrm{~A} \mathrm{a}$ & $70 \mathrm{~A} \mathrm{a}$ \\
\hline E3 & $52 \mathrm{~A} \mathrm{~b}$ & $69 \mathrm{~A} \mathrm{a}$ & $69 \mathrm{~A} \mathrm{a}$ \\
\hline
\end{tabular}

Médias seguidas pela mesma letra maiúscula na coluna e minúscula na linha, não diferem entre si, pelo Teste de Scott-Knott, ao nível de $5 \%$ de probabilidade. 
Segundo NASCIMENTO et. al., (2006) frutos imaturos, de coloração verde, geralmente produzem sementes com baixo vigor e poder germinativo ou até inférteis. Segundo SANCHEZ et al. (1993) sementes de pimentão devem permanecer no fruto maduro (idade de 50 dias após antese) após a colheita, de 7 a 14 dias, para que o potencial máximo de germinação seja atingido, havendo quebra de dormência.

A imaturidade dessas sementes do estádio E1 foi comprovada pelo perfil enzimático da enzima endo- $\beta$-mananase, em que houve aumento da atividade em sementes (Figura 1) processadas nos estádios de desenvolvimento mais avançados, E2 e E3. Isto se deve ao fato de a enzima endo- $\beta$-mananase estar envolvida na degradação do endosperma na germinação das sementes. Em sementes de alface e café esta enzima é considerada chave no processo de germinação, estando envolvida na degradação de mananas no momento da germinação, resultando no enfraquecimento das paredes celulares do endosperma (SILVA et al., 2004). Foi observada ainda menor atividade da enzima nas sementes recém-armazenadas independente do estádio de desenvolvimento das sementes.

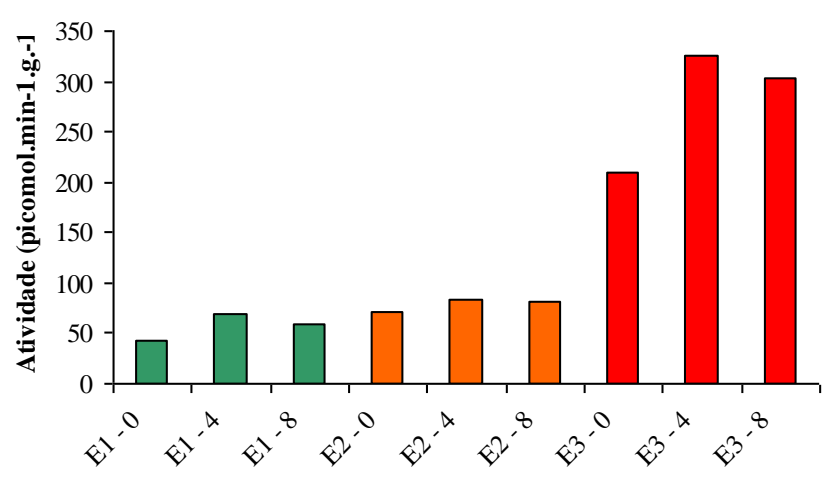

Figura 1 - Atividade da enzima endo- $\beta$-mananase em sementes de pimenta malagueta processadas nos estádios de desenvolvimento E1 (frutos amarelados), E2 (frutos maduros) e E3 (frutos maduros com 7 dias de repouso) em três períodos de armazenamento 0, 4 e 8 meses. Activity of endo- $\beta$ mannanase in chilli seeds processed in developmental stages E1 (yellow fruit), E2 (ripe fruit) and E3 (ripe fruit with 7 days rest) in three periods of storage 0, 4 and 8 months.

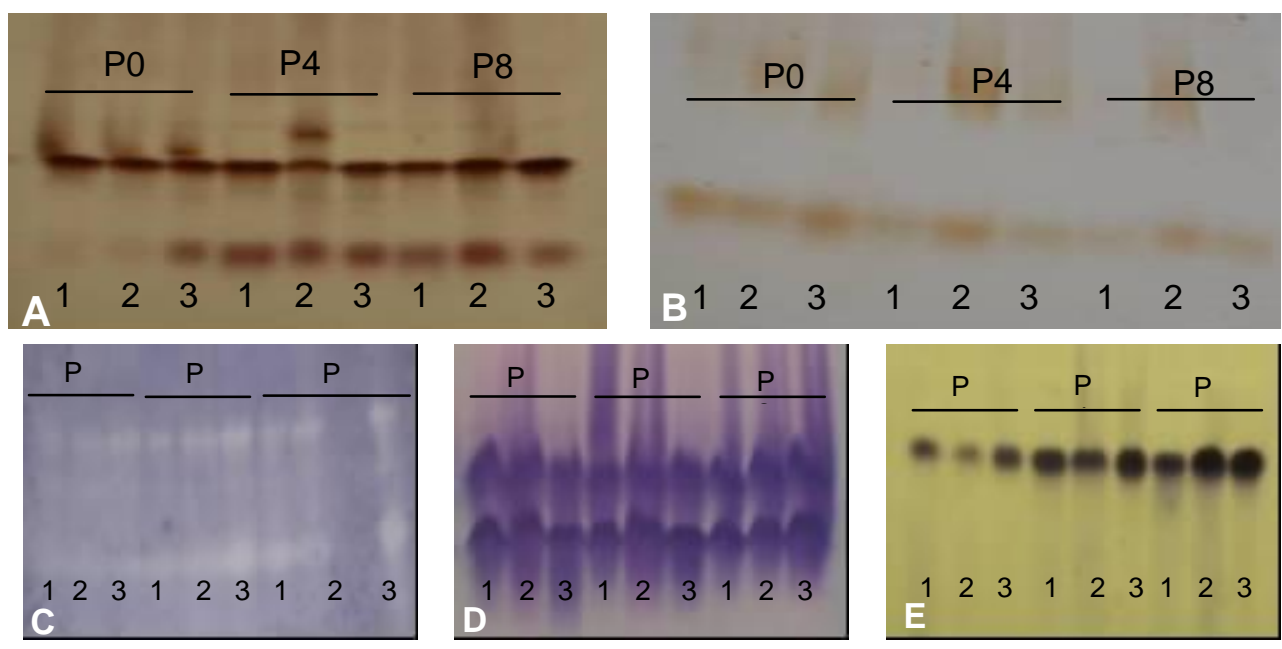

Figura 2 - Perfis enzimáticos da esterase (A), peroxidase (B), SOD (C), MDH (D) e ADH (E) de sementes de pimenta malagueta processadas nos estádios P1 (frutos amarelados) (1), P2 (frutos maduros) (2) e P3 (frutos maduros com 7 dias de repouso) (3), nos três períodos de armazenamento 0 (P0), 4 (P4) e 8 (P8) meses. Esterase enzyme profiles (A), peroxidase (B), SOD (C), MDH (D) and $D H A(E)$ of chili pepper seed processed in stages $P 1$ (yellow fruits) (1), P2 (ripe fruit) (2) and P3 (ripe fruit with 7 days off) (3) in the three periods of storage 0 (PO), 4 (P4) and 8 (P8) months. 
Tabela 2 - Valores médios de condutividade elétrica, obtidos em sementes de pimenta malagueta colhidas em diferentes estádios de desenvolvimento ao longo do armazenamento. Mean values of electrical conductivity, obtained from seeds of chillies harvested at different stages of development during storage.

\begin{tabular}{lccc}
\hline \multicolumn{1}{c}{ Estádios } & $\begin{array}{c}\text { Condutividade elétrica } \\
\left(\mu \mathrm{cm}^{-1} \mathrm{~g}^{-1}\right)\end{array}$ & $\begin{array}{c}\text { Períodos } \\
(\text { meses })\end{array}$ & $\begin{array}{c}\text { Condutividade elétrica } \\
\left(\mu \mathrm{cm}^{-1} \mathrm{~g}^{-1}\right)\end{array}$ \\
\hline E1 (Frutos amarelados) & $801 \mathrm{~b}$ & 0 & $681 \mathrm{a}$ \\
E2 (Frutos maduros) & $760 \mathrm{a}$ & 4 & $691 \mathrm{a}$ \\
E3 (Frutos maduros com 7 dias de & $750 \mathrm{a}$ & 8 & $938 \mathrm{~b}$ \\
repouso) & &
\end{tabular}

Médias seguidas pela mesma letra na coluna não diferem entre si pelo Teste de Scott-Knott ao nível de 5\% de probabilidade.

A germinação das sementes de pimenta malagueta processadas nos estádios E1, E2 e E3 foi aumentada no quarto mês de armazenamento (Tabela 1). Esse resultado pode estar relacionado à presença de dormência nas sementes a qual foi quebrada ao longo do armazenamento, já que na avaliação do teste de germinação em sementes recém-armazenadas foi observada a presença de sementes embebidas, sem protrusão radicular, viáveis sem quaisquer sintomas de deterioração constatados pelo teste de tetrazólio (dados não apresentados). Esses resultados corroboram os encontrados por BOSLAND \& VOTAVA (1999), nos quais houve dormência nas sementes recém-colhidas de espécies do gênero Capsicum.

A quebra desta dormência aos quatro meses de armazenamento pode ser evidenciada pelo perfil enzimático da enzima SOD, em que, Figura 2C, maior atividade foi observada em sementes processadas no estádio E3 e armazenadas por quatro e oito meses. Essa enzima catalisa os radicais superóxidos livres $\left(\mathrm{O}_{2}^{-}\right)$, produzidos em diferentes locais da célula, para oxigênio molecular e $\mathrm{H}_{2} \mathrm{O}_{2}$ (MCDOLNALD, 1999).

$\mathrm{Na}$ presente pesquisa, sementes de pimenta malagueta processadas no estádio E3 e armazenadas por 4 meses foram observadas maiores valores de germinação e de vigor (Tabelas 1 e 2). VIDIGAL et al. (2009) observaram pequeno aumento na intensidade das bandas da SOD nas sementes de pimenta malagueta obtidas de frutos colhidos a partir de 50 DAA e armazenados por 6 dias.

No oitavo mês de armazenamento foi observada redução na germinação em relação à observada no quarto mês de armazenamento. A redução na germinação com o armazenamento das sementes pode ser atribuída à maior deterioração. Esse resultado também foi observado no teste de emergência de plântulas (Tabela 1). Esta deterioração pode também ser observada pelos perfis enzimáticos das enzimas relacionadas com a respiração: $M D H$ (Figura 2D) e ADH (Figura 2E). A MDH catalisa a conversão de malato a oxalacetato e participa do movimento de malato através da membrana mitocondrial e da fixação de $\mathrm{CO}_{2}$ nas plantas (TAIZ \& ZEIGER, 2004). Por outro lado maior atividade dessa enzima foi observada em sementes processadas nos estádios E2 e E3 e armazenadas por oito meses. Já a $A D H$ está relacionada à respiração anaeróbica, promovendo redução do acetaldeído a etanol (BUCHANAN et al., 2005). O aceltadeído acelera a deterioração das sementes (ZHANG et al., 1994). Com o aumento da atividade da $A D H$, as sementes ficam mais protegidas contra a ação deletéria deste composto, a qual é maior quanto comparada a do etanol.

A enzima $\mathrm{MDH}$ teve atividade reduzida em sementes processadas no estádio E1, em todos os períodos de armazenamento, caracterizando redução na respiração aeróbica, uma vez que essa enzima tem uma função importante no ciclo de Krebs para a produção de NADH. Quanto ao sistema enzimático da ADH (Figura $2 E)$, foi observada maior atividade em sementes armazenadas aos quatro e oito meses. Ainda foi observada maior atividade dessa enzima nas sementes processadas no estádio E3, quando recém-armazenadas e aos quatro meses de armazenamento. Resultados semelhantes foram encontrados por VIDIGAL et al. (2009).

Menores valores de emergência de plântulas foram observados em sementes processadas no estádio de desenvolvimento $\mathrm{E} 1 \mathrm{em}$ todos os períodos de armazenamento, com exceção dos observados no quarto mês de armazenamento. Menores valores de emergência foram observados em sementes imaturas. Esse resultado também foi observado no índice de velocidade de emergência (IVE) (Tabela 1). É importante ressaltar também que apesar dos relatos sobre a ocorrência de dormência em sementes de pimenta, há também referências nas quais é mencionado o sucesso no estabelecimento de plântulas em casa de vegetação, onde não houve diferença estatística entre os diferentes estádios. Segundo NASCIMENTO et al. (2006), a semeadura de sementes de pimenta recémextraídas do fruto pode representar um risco para a obtenção de estandes uniformes, contribuído para a elevação do gasto de sementes.

Aos quatro meses de armazenamento 
houve aumento nos valores de emergência de plântulas provenientes de sementes processadas nos diferentes estádios de desenvolvimento, com exceção das sementes processadas no estádio E2. Houve redução desses valores aos oito meses de armazenamento para as sementes colhidas no estádio E1 (Tabela 1). No período zero de armazenamento foram observadas em sementes do estádio E3, maiores valores de emergência de plântulas. Essa diferença não foi observada aos quatro meses de armazenamento. Já aos oito meses de determinadas cultivares são extraídas de frutos completamente maduros e semeadas em seguida (BOLSLAND, 1999). RANDLE \& HONMA (1981) verificaram em trabalho com diferentes cultivares do gênero Capsicum, que o genótipo e a idade do fruto influenciam na intensidade de dormência das sementes. Os autores afirmam que sementes extraídas de frutos supermaduros germinam mais rapidamente, havendo aumento da intensidade de dormência com o decréscimo da idade do fruto.

Pelos resultados do IVE, foi observado menor vigor em sementes colhidas no estádio E1. Neste teste observou-se aumento de vigor nas sementes armazenadas por quatro meses e processadas nos três estádios. No entanto, aos oito meses houve aumento de vigor das processadas no $E 3$, redução nas colhidas no $E 1$ e manutenção das colhidas no E2. Estes resultados de certa forma corroboram com os obtidos por BARBEDO et al. (1999), que ao trabalharem com sementes de pepino também verificaram um aumento crescente das características de vigor em estádios mais avançados de maturação do fruto, com e sem repouso. Além disso, o potencial de armazenamento das sementes de pepino aumenta quando as sementes são colhidas próximo ao ponto de maturidade fisiológica. No caso das sementes de pimenta, esta maturidade provavelmente ocorre quando os frutos estão vermelhos (E2).

Quanto aos resultados do teste de enveIhecimento acelerado (Tabela 1), verificou-se aumento no vigor das sementes armazenadas aos quatro meses, em relação às sementes recém- armazenadas. Embora tenha ocorrido redução no vigor das sementes colhidas no estádio E1 aos oito meses de armazenamento, não foi observada diferença estatística significativa. No início do armazenamento, sementes processadas no E3, mostraram-se mais vigorosas. Já aos quatro e oito meses de armazenamento não houve diferença estatística entre os valores de vigor observados nas sementes processadas nos estádios E2 e E3.

No teste de envelhecimento acelerado, o vigor foi crescente até o quarto mês de armazenamento em todos os estádio de desenvolvimento. Esses resultados são similares aos observados em tomate (VIDIGAL et al., 2006; DIAS et al., 2006) e abóbora italiana (ALVARENGA et al., 1991). Este vigor crescente, observado também pela maior atividade da enzima peroxidase (Figura 2B), foi encontrado em sementes recém-armazenadas em todos os estádios de desenvolvimento. A peroxidase desempenha papel crítico no metabolismo das sementes, por utilizar peróxidos como aceptor de hidrogênio, podendo contribuir para o aumento dos mecanismos de defesa e prevenção de perda na qualidade (USHIMARU et al., 2001). De acordo com BEWLEY \& BLACK (1994), a redução da atividade dessa enzima proporciona maior exposição dos sistemas de membranas aos efeitos do $\mathrm{O}_{2}$. Com isso, em decorrência do nível de danos das membranas, o oxigênio atua de forma mais intensa, promovendo oxidação dos compostos.

De uma maneira geral, maior atividade dessa enzima foi observada em sementes recém-armazenadas (P0). Durante o armazenamento houve redução da atividade dessa enzima, nas sementes processadas nos estádios de desenvolvimento E1 e E3 (Figura 2B). Maior lixiviação de exudatos foi observada em sementes imaturas em função de menor estruturação do sistema de membranas das organelas e celular. Da mesma, forma, maior lixiviação também foi observada aos oito meses de armazenamento (Tabela 2). Entretanto, o alto valor de condutividade observado para sementes colhidas no E1 sugere desestruturação do sistema de membranas, provavelmente por causa da imaturidade das mesmas (ALBUQUERQUE et al., 2009), fato este reforçado também pelos resultados dos outros testes fisiológicos (Tabela 2).

Corroborando os resultados dos demais testes de vigor, menores valores de condutividade elétrica foram obtidos com o aumento da idade dos frutos, indicando maior organização do sistema de membranas das sementes com 0 decorrer da maturação. Por outro lado, o alto teor de gordura das sementes favorece, neste grupo de enzimas hidrolíticas, a liberação de ácido graxo dos lipídios, os quais são usados na beta oxidação, como fonte de energia para os eventos germinativos (SANTOS et al., 2004). Isto pode ser evidenciado pelo perfil enzimático da enzima esterase, em que foi observado aumento na atividade enzimática no estádio de desenvolvimento E3 (sementes recém-armazenadas), o que parece estar associado ao acúmulo de lipídeos nas sementes (Figura 2A). De uma maneira geral, em sementes recém-armazenadas ( $P 0)$, maiores valores de vigor e germinação forma observados naquelas processadas no estádio de desenvolvimento E3 (Tabelas 1 e 2). Dessa forma, infere-se que os lipídeos presentes nas sementes tenham sido utilizados como fonte de 
energia durante o processo de germinação. Segundo BOSLAND \& VOTAVA (1999) em sementes de pimenta há $26,1 \%$ de óleo o que justifica tal resultado. Aos quatro e oito meses de armazenamento não foram observadas alterações nos padrões dessa enzima em sementes processadas nos diferentes estádios de desenvolvimento.

A esterase é uma enzima que participa da hidrólise de ésteres de membrana. Esse fato demonstra maior peroxidação de lipídios, uma vez que esta enzima está envolvida em reações de hidrólise de ésteres estando diretamente ligada ao metabolismo de lipídios (SANTOS et al., 2004). Muitos desses lipídios são constituintes de membranas, cuja degradação aumenta com a deterioração.

Considerando as análises eletroforéticas das enzimas durante a germinação observou-se que não houve diferença na atividade das enzimas nas sementes secas, embebidas por 0 hora, daquelas embebidas por 48 horas em todos os padrões enzimáticos, com exceção da observada para enzima endo- $\beta$-mananase.

Foram verificadas variações nos padrões da enzima MDH (Figura 3A) com o avanço do processo de germinação. Tanto nas sementes recém-armazenadas quanto naquelas armazenadas por quatro meses, houve atividade maior da enzima até 96 horas de embebição da semeadura, com redução da mesma no período de 144 horas. Nas sementes armazenadas por período de oito meses, foi observada maior atividade dessa enzima no período de 144 horas de embebição. Infere-se que nas sementes recémarmazenadas e naquelas armazenadas por quatro meses a respiração aeróbica seja maior no início do processo de germinação. Ressalta-se ainda, que a maior porcentagem de protrusão radicular foi observada aos 4 dias da semeadura. Já no oitavo mês de armazenamento, pelo fato das sementes estarem em estádios mais avançados de deterioração há maior intensidade respiratória e consequentemente maior demanda de atividade da enzima MDH nas sementes de pimenta malagueta.

A MDH desempenha um papel significativo no ciclo de Krebs, uma vez que catalisa a conversão de malato a oxaloacetato, produzindo $\mathrm{NADH}$, que é um produto fundamental na produção de ATP e de compostos intermediários necessários ao funcionamento da célula (TAIZ \& ZEIGER 2004). Portanto essa enzima constitui um eficiente marcador da respiração aeróbica das sementes durante a maturação e germinação de sementes.

Em relação aos padrões observados para a enzima $A D H$, maior atividade foi observada em sementes recém-armazenadas submetidas à embebição por 144 horas e em sementes armazenadas por quatro meses e submetidas à embebição por 96 e 144 horas (Figura 3B). Houve variação na atividade da enzima $A D H$ em sementes processadas em diferentes estádios de maturação, em função do período de armazenamento e do período de embebição. Em geral, nessas condições, maior atividade da $\mathrm{ADH}$ foi observada em sementes processadas no estádio E3, após 96 horas de embebição, nos três períodos de armazenamento (Figura 3B). Esses resultados corroboram os de germinação e vigor, em que as sementes processadas nos estádios E2 e E3 possuem maior qualidade do que as sementes do estádio E1.

Em relação aos padrões observados para a enzima esterase (Figura $3 \mathrm{C}$ ) foi observado naquelas processadas no estádio E2 de maturação, recém-armazenadas e armazenadas por período de quatro meses, o aparecimento de uma banda quando as mesmas foram submetidas à embebição por 96 horas. Já nas sementes armazenadas por período de oito meses os padrões observados foram diferenciados dos demais. Houve maior atividade dessa enzima independente do estádio de maturação das sementes e do período de embebição.

Para os padrões da enzima $\alpha$-amilase (Figura 3D), observa-se que houve variação na atividade da enzima em função do estádio de desenvolvimento no qual as sementes foram processadas, período de armazenamento e tempo de exposição à embebição.

Em sementes recém-armazenadas (P0), houve aumento na atividade da enzima $\alpha$-amilase com o aumento do período de exposição à embebição e com o avanço no estádio de maturação. Já nas sementes armazenadas por quatro meses houve maior atividade da enzima quando processadas no estádio de desenvolvimento E1, quando comparada à observada em sementes recém-armazenadas. Nessas sementes, armazenadas por quatro meses, houve aumento de atividade da $\alpha$-amilase quando foram processadas no estádio de desenvolvimento E3 e embebidas por 96 e 144 horas. De uma maneira geral, menor atividade da enzima $\alpha$-amilase foi observada em sementes armazenadas por período de oito meses. Nessas sementes maior atividade da enzima foi observada quando embebidas por 96 horas.

De acordo com NEDEL et al. (1996), dentro de um grupo de enzimas, a $\alpha$ e $\beta$ - amilases estão envolvidas no principal sistema de degradação do amido. O desenvolvimento da atividade da amilase constitui um importante evento, podendo ser detectado durante o início da germinação das sementes, sendo seu principal papel, disponibilizar substratos para utilização da plântula até que ela se torne fotossinteticamente autossuficiente. 
Um grande número de tipos de dormência de sementes decorre do bloqueio da ação da $\alpha$-amilase. A $\alpha$-amilase presente nas sementes dormentes encontra-se em pequenas quantidades. $A$ atividade da $\alpha$-amilase aumenta à medida que a dormência das sementes de arroz e superada, durante o período de armazenamento (VIEIRA, et. al. 2008).

$\mathrm{Na}$ presente pesquisa, por meio dos dados de germinação (Tabela 1), foi observada a presença de sementes dormentes, principalmente quando processadas no estádio $\mathrm{E} 1$ de desenvolvimento, recém-armazenadas. Nessas sementes foi observada baixa atividade da $\alpha$ amilase, o que confirma a importância dessa enzima no processo de germinação de sementes de pimenta.

Nas sementes processadas nos estádios de desenvolvimento E1, E2 e E3 e recém-armazenadas (P0), houve aumento na atividade da enzima endo- $\beta$-mananase (Figura 4) à medida que foi aumentado o período de embebição das sementes, durante o processo de germinação. Houve maior atividade dessa enzima a 144 horas de embebição o que coincidiu com o período observado para a ocorrência de protrusão radicular. As sementes dos três estádios de desenvolvimento, armazenadas por quatro e oito meses, germinaram com 96 horas de embebição. Esses dados podem ser correlacionados com a maior atividade dessa enzima em sementes submetidas a esses tratamentos.
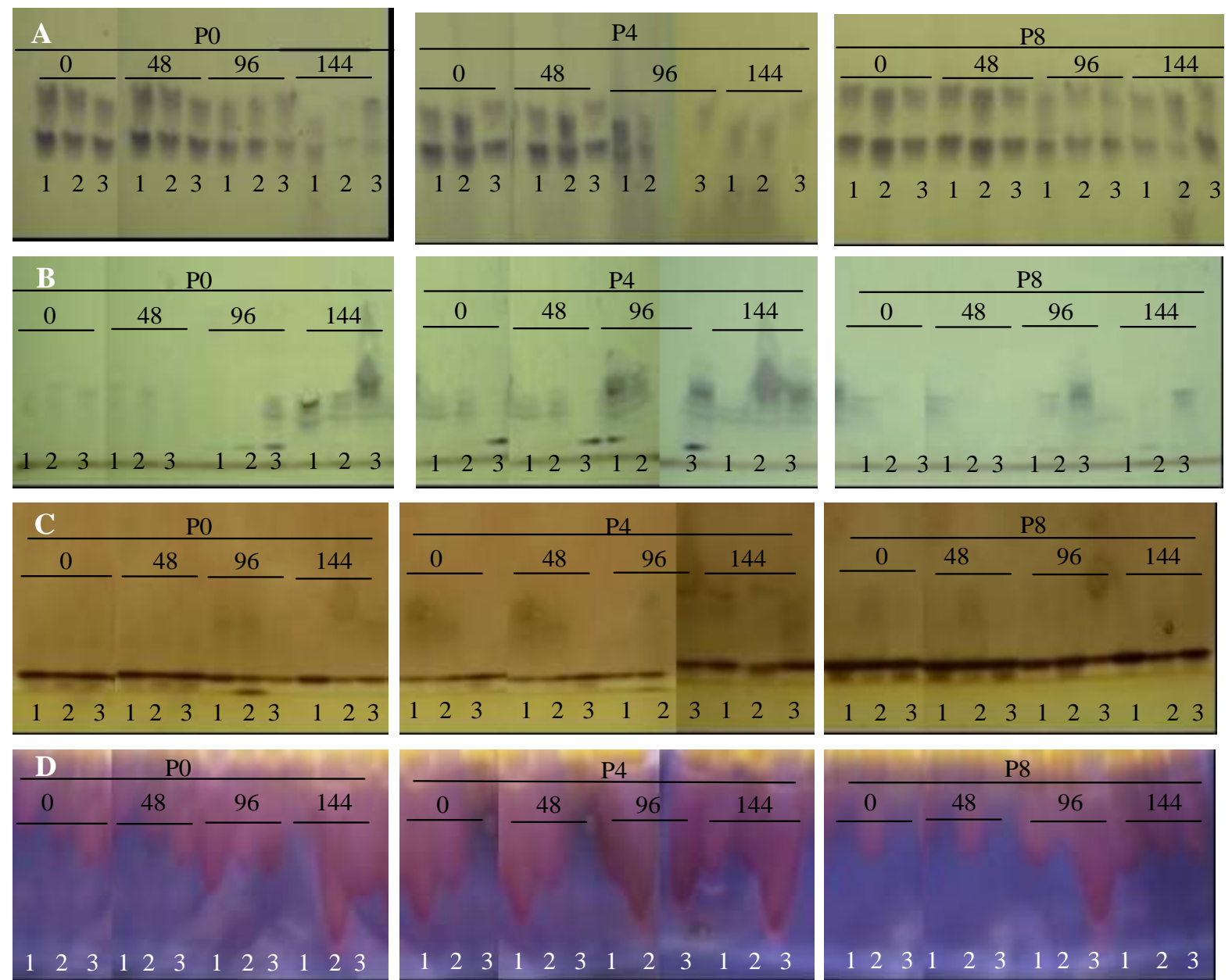

Figura 3 - Padrões eletroforéticos da enzima $\mathrm{MDH}(\mathrm{A}), \mathrm{ADH}(\mathrm{B})$, esterase (C) e $\alpha$-amilase (D) observados em sementes de pimenta malagueta durante a germinação: 0 hora; 48 horas; 96 horas e 144 horas no estádio E1 (frutos amarelados) (1), E2 (frutos maduros) (2) e E3 (frutos maduros com 7 dias de repouso) (3) com 0 (P0), 4 (P4) e 8 (P8) meses de armazenamento. Eletrophoresis the enzyme $\mathrm{MDH}(A), A D H(B)$, esterase $(C)$ and $\alpha$-amylase $(D)$ found in chili pepper seeds during germination: 0 hours $(A), 48$ hours $(B), 96$ hours $(C)$ and 144 hours $(D)$ in stage $E 1$ (yellow fruits) (1), E2 (ripe fruit) (2) and E3 (ripe fruits after 7 days of rest (3)) with 0 (P0), fourth (P4) and 8 (P8) months of storage. 
A

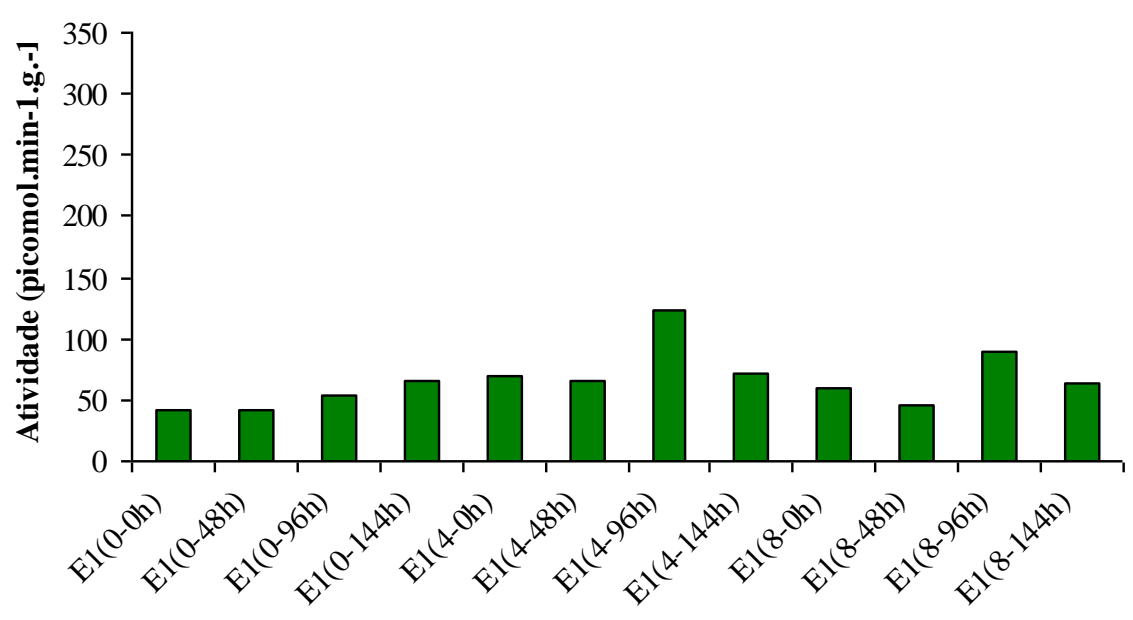

B

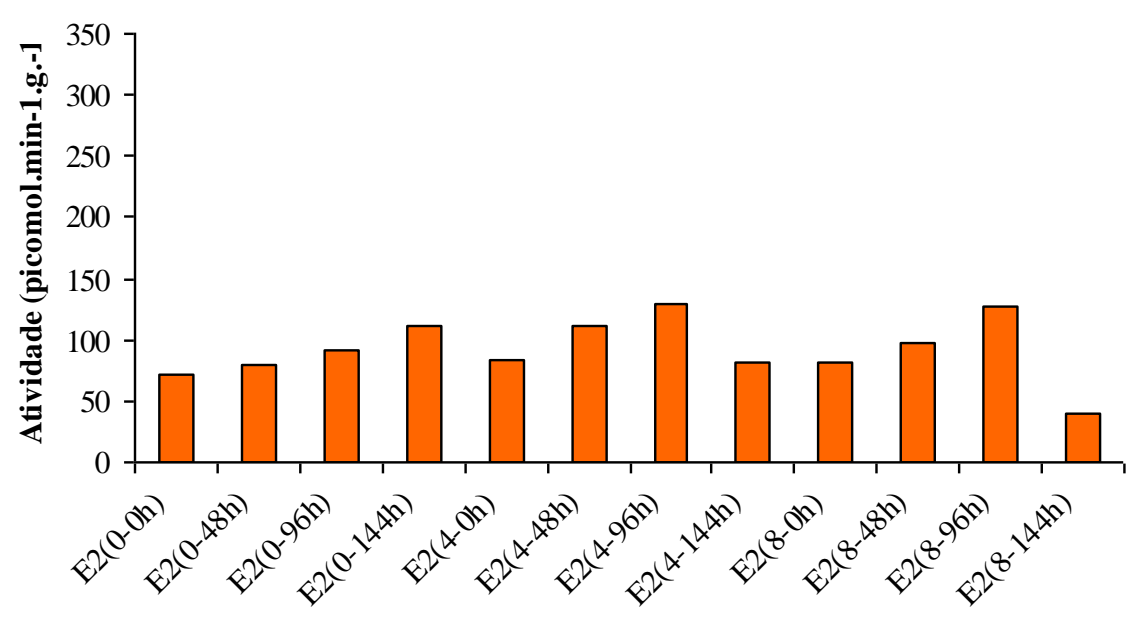

C

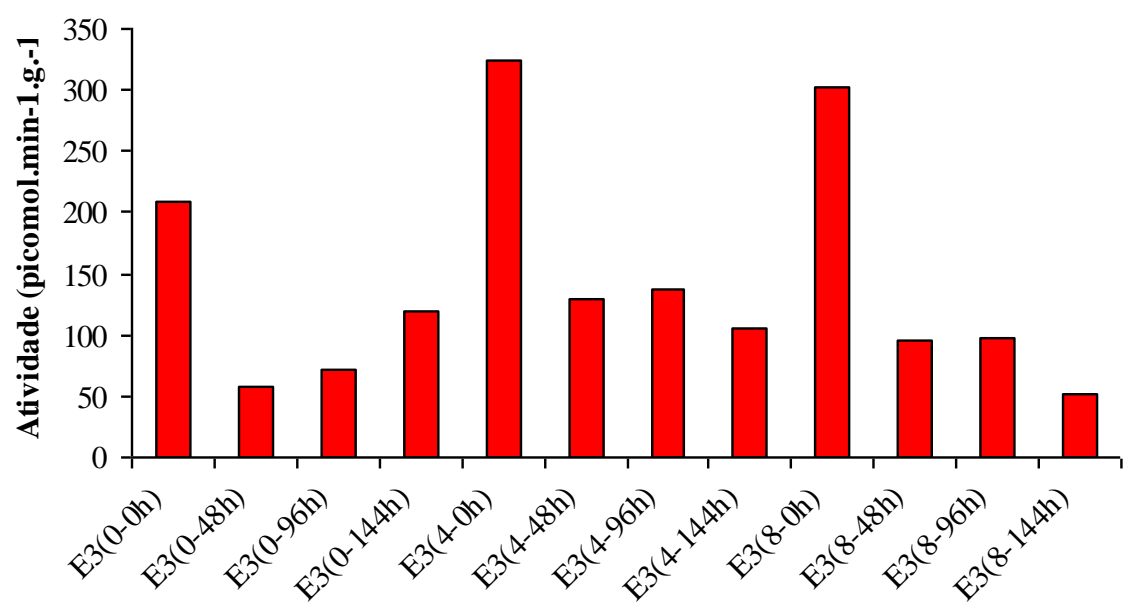

Figura 4 - Atividade da enzima endo- $\beta$-mananase em sementes de pimenta malagueta durante 0 hora, 48 horas, 96 horas e 144 horas de germinação no estádio E1 (frutos amarelados) (A), E2 (frutos maduros) (B) e E3 (frutos maduros com 7 dias de repouso) (C)nos três períodos de armazenamento 0,4 e 8 meses. Activity of endo- $\beta$-mannanase in chilli seeds for 0 hour, 48 hours, 96 hours and 144 hours in the germination stage E1 (yellow fruit) $(A), E 2$ (mature fruits) $(B)$ and E3 (ripe fruit with 7 days rest) $(C)$ in all three storage periods 0,4 and 8 months. 
Maior atividade da enzima, em valores absolutos, foi verificada nas sementes processadas nos estádios de desenvolvimento E2 e E3 em todos os períodos de armazenamento e de embebição, durante o processo de germinação. Os menores valores de germinação e de vigor foram observados nas sementes processadas no estádio de desenvolvimento E1 e recém-armazenadas. Nessas sementes foi observada menor atividade da enzima endo- $\beta$-mananase, o que indica a importância dessa enzima na germinação de sementes de pimenta.

Pelos resultados dos testes utilizados para a avaliação da qualidade fisiológica foi observado aumento nos valores de germinação e de vigor em sementes armazenadas por período de quatro meses. Com base nesses resultados infere-se a presença de dormência em sementes recém colhidas. Essa dormência provavelmente tenha sido superada no quarto mês de armazenamento em função da maior atividade da enzima endo- $\beta$-mananase.

Para BEWLEY \& BLACK (1994), em algumas sementes a germinação ocorre devido ao enfraquecimento dos tecidos que circundam o embrião permitindo, dessa forma, o alongamento da radícula. Neste caso, o potencial de pressão (чp) no embrião não é suficiente para levar à expansão das paredes celulares e crescimento do mesmo. A redução da resistência mecânica, imposta pelo endosperma, ao alongamento da radícula é controlada pela ação de enzimas como endo- $\beta$-mananase. Em sementes de café (Coffea arabica), a degradação do endosperma micropilar é devida à ação da enzima endo- $\beta$ mananase facilitando a emissão da raiz primária (SILVA et al., 2004).

Em síntese observa-se por meio dos testes fisiológicos e pela atividade das enzimas avaliadas que as sementes de pimenta malagueta devem ser colhidas quando os frutos estiverem maduros e serem extraídas após 7 dias de repouso (E3) quando forem comercializadas logo após o processamento. Caso as sementes sejam armazenadas por períodos acima de quatro meses poderão ser processadas a partir de frutos colhidos nos estádios de desenvolvimento E2 ou E3. Nesse aspecto observa-se que ponto de maturidade fisiológica das sementes dessas espécies não coincide com os valores máximos de germinação e vigor em função da incidência de dormência.

\section{Conclusões}

Existe dormência em sementes de pimenta malagueta principalmente quando recémarmazenadas e é superada aos quatro meses de armazenamento.

A dormência é amenizada quando as sementes permanecem em repouso nos frutos (E3).

Sementes de pimenta malagueta devem ser colhidas no estádio E3 quando forem comercializadas logo após o processamento e nos estádios E2 ou E3 quando armazenadas por períodos acima de quatro meses.

As alterações enzimáticas são evidentes no processo de germinação e nos diferentes estádios de maturação durante o armazenamento.

As enzimas alfa amilase e endo- $\beta$ mananase são importantes no processo de germinação de sementes de pimenta malagueta.

\section{Referências}

ALBUQUERQUE, K. S.; GUIMARÃES, R. M.; GOMES, L. A. A.; VIEIRA, A. R.; JÁCOME, M. F. Condicionamento osmótico e giberelina na qualidade fisiológica de sementes de pimentão colhidas em diferentes estádios de maturação. Revista Brasileira de Sementes, Viçosa, MG, v.31, n.4, p.100-109, 2009.

ALFENAS, A. C. Eletroforese e marcadores bioquímicos em plantas e microrganismos. 2 ed. Viçosa: Editora UFV, 2006. 627p.

ALVARENGA, E. M.; SILVA, R. F.; ARAUJO, E. F.; LEIRO, L. S. Maturação fisiológica de sementes de abóbora italiana. Revista Brasileira de Sementes, Viçosa, MG, v.13, n.2, p.147-150, 1991.

BARBEDO, C. J.; BARBEDO, A. S. C.; NAKAGAWA, J.; SATO, O. Efeito da idade e do repouso pós-colheita de frutos de pepino na semente armazenada. Pesquisa Agropecuária Brasileira, Brasília, v.34, n 5, p.839-47, 1999.

BEWLEY, J. D.; BLACK, M. Seed: physiology of development and germination. $2^{\text {nd }}$ ed. New York: Plenum Press, 1994. 445p.

BOSLAND, P. W.; VOTAVA, E. J. Peppers: vegetable and spice capsicums. Wallingford: CAB International, 1999. 204p. (Crop Production Science in Horticultire, 12).

BRASIL. Ministério da Agricultura e Reforma Agrária. Regras para análises de sementes. Brasília: SNDA/DNDV/CLAV, 2009. 398p.

BUCHANAN, B. B.; GRUISSEM, W.; JONES, R. $\mathrm{L}$. Biochemistry e molecular biology of plants. Rockville: American Society of Plant Physiologists, 2005. 1367p.

CAIXETA, F.; VON PINHO, E. V. R.; GUIMARÃES, R. M.; PEREIRA, P. H. A. R.; CATÃO, H. C. R. M. Physiological and biochemical alterations during germination and storage of habanero pepper seeds. African Journal of Agricultural Research, Joannesburgo, v.9, n.6, p.627-635, 2014. 
DIAS, D.C.F.S.; RIBEIRO, F.P.; DIAS, L.A.S.; SILVA, D.H.; VIDIGAL. D.S. Tomato seed quality in relation to fruit maturation and post-harvest storage. Seed Science and Technology, Bassersdorf, v.34, n.3, p.691-699, $2006 a$.

DOWNIE, B.; HILLHORST, H. W. M.; BEWLEY, J. $D$. A new assay for quantifying endo- $\beta$-mananase activity using Congo Red dye. Phytochemistry, Oxford, v.36, n.4, p. 829-835, july 1994.

FERREIRA, D. F. Análises estatísticas por meio do SISVAR para Windows ${ }^{\circledR}$ versão 4.0. In: REUNIÃO ANUAL DA REGIÃO BRASILEIRA DA SOCIEDADE INTERNACIONAL DE BIOMETRIA, 45. 2000, São Carlos. Programas e Resumos... São Carlos: UFSCar, 2000. p.235.

FILGUEIRA, F. A. R. Novo manual de olericultura: agrotecnologia moderna na produção e comercialização de hortaliças. Viçosa: UFV, 2000. 402p.

FILGUEIRA, F. A. R. Solanáceas: agrotecnologia moderna na produção de tomate, batata, pimentão, pimenta, berinjela e jiló. Lavras: UFLA, 2003.333p.

FILGUEIRA, F.A. Novo manual de olericultura: agrotecnologia moderna na produção e comercialização de hortaliças. 2.ed. Viçosa: Editora UFV, 2005. 412p.

MAGUIRE, J. D. Speed of germination and relation evaluationfor seedling emergence vigor. Crop Science, Madison, v.2, p.176-177, 1962.

McDONALD, M. B. Seed deterioration: physiology, repair and assessment. Seed Science and Technology, Bassersdorf, v.22, n.3, p.531-539, 1999.

NASCIMENTO, W.M.; DIAS, D.C.F.S.; FREITAS, R.A. Produção de sementes de pimentas. Informe agropecuário: Cultivo da pimenta, Belo Horizonte, v.27, n.235, p.30-39, 2006.

RANDLE, W. M.; HONMA, S. Dormancy in peppers. Scientia Horticulturae, Alexandria, v.14, p.19-25, 1981.

SANCHEZ, V. M.; SUNDSTROM, G. N.; McCLURE, G. N.; LANG, N. S. Fruit maturity, storage and postharvest maturation treatments affect bell pepper (Capsicum annuum L.) seed quality. Scientia Horticulturae, Alexandria, v.54, n.3, p.191-201, 1993.

SANTOS, C. M. R.; MENEZES, N. L.; VILELA, F. A. Alterações fisiológicas e bioquímicas em sementes de feijão envelhecidas artificialmente. Revista Brasileira de Sementes, Viçosa, MG, v.26, n.1, p.110-119, 2004.
SILVA, E. A. A.; TOOROP, P. E.; AELST, A. C.; HILHORST, H. W. M. Abscisic acid controls embryo growth potential and endosperm cap weakening during coffee (Coffea arabica cv. Rubi) seed germination. Planta, Berlin, v.220, n.2, p.251-261, 2004.

TAIZ, L.; ZEIGER, E. Fisiologia vegetal. 3. ed. Porto Alegre: Artmed, 2004. cap. 11, p. 317-327.

TORRES, S. B. Envelhecimento acelerado em sementes de pimenta-malagueta (Capsicum frutescens L.). Revista Ciência Agronômica, Fortaleza, v.36, n.1, p.98-104, jan./abr. 2005.

USHIMARU, T.; KANEMATSU, S.; KATAYAMA, M.; TSUJI, $H$. Antioxicidative enzymes in seedlling of Nelumbo nucifera germinated under water. Physiologia Plantarum, Copenhagen, v.112, n.1, p.39-46, 2001.

VIDIGAL, D.S.; DIAS, D.C.F.S.; NAVEIRA, D.S.P.; ROCHA, F.B.; BHERING, M.C. Alterações fisiológicas e enzimáticas durante a maturação de sementes de pimenta (Capsicum annuum L.). Revista Brasileira de Sementes, Viçosa, MG, v.31, n.2, p.129-136, 2009.

VIDIGAL, D.S.; DIAS, D.C.F.S.; PINHO, E. V. R. V.; DIAS, L. A. S. Qualidade fisiológica de sementes de tomate em função da idade e do armazenamento pós-colheita dos frutos. Revista Brasileira de Sementes, Viçosa, MG, v.28, n.3, p.87-93, 2006.

VIDIGAL, D.S.; LIMA, J.S.; BHERING, M.C; DIAS, D.C.F.S. Teste de condutividade elétrica para sementes de pimenta. Revista Brasileira de Sementes, Viçosa, MG, v.30, n.1, p.168-174, 2008.

VIEIRA, A. R.; OLIVEIRA, J. A.; GUIMARÃES, R. M.; PINHO, E. V. R. V.; PEREIRA, C. E.; CLEMENTE, A. C. S. Marcador isoenzimático de dormência em sementes de arroz. Revista Brasileira de Sementes, Viçosa, MG, v.30, n.1, p.81-89, 2008.

ZHANG, M.; MAEDA, Y.; FUTIHATA, Y.; NORAMURA, Y.; ESASHI, Y. A machanism of seed deterioration in relation to volatile compounds evoked by dry seeds themselves. Seed Science Research, Wallingford, v.4, n.1, p.49-56, 1999. 